\title{
Effect of physical therapy in daily life and work activities for people with chronic cervical pain syndrome
}

\author{
Eldad Kaljić* Edina Hadžipašić, Amila Jaganjac, Namik Trtak, Bakir Katana, Muris Pecar \\ Department of Physiotherapy, Faculty of Health Studies, University of Sarajevo, Sarajevo, Bosnia and Herzegovina
}

\begin{abstract}
Introduction: Cervical pain syndrome (CPS), or pain in the neck, is defined as a set of symptoms that limit performing movements in the upper part of the back and last more than 1 day. When the mentioned symptoms last for more than 12 weeks, we talk about chronic CPS. It often represents the condition that results from disability. It is associated with poor posture, work in sitting position, stress, and long-lasting and repetitive movements. The aim of the study was to examine the effect of physical therapy on the degree of disability, pain intensity, and daily life and work activities of persons with chronic CPS.

Methods: The research was conducted in the health spa center "Reumal" Fojnica from June 2020 until July 2020. It included 50 subjects of both genders, more than 18 years old, and of all occupations, treated with physiotherapy procedures (transcutaneous electrical nerve stimulation, magnetotherapy, therapeutic ultrasound, and kinesitherapy in the form of McKenzie exercises). In addition, a pre- and post-treatment study analyzed the condition of the respondents at the first examination and the control examination after completion of treatment.

Results: By analyzing the results, we established that of the total number of respondents, $74 \%$ were female, and the average age was 57.36 years. At the end of the study, the degree of disability caused by neck pain was significantly lower $(p<0.05)$ than the degree of disability before the therapy. Discomfort caused by symptoms of CPS that occurred and interference with work before the therapy was significantly lower $(p<0.05)$ after the treatment program. Therapeutic procedures have reduced the pain intensity and improved the activities of everyday life.
\end{abstract}

Conclusion: The treatment with physical therapy procedures effectively reduces the degree of disability and pain intensity and improves people's daily life and work activities with chronic CPS.

Keywords: Chronic cervical pain syndrome; physical therapy; pain; daily life activities; work activities

\section{INTRODUCTION}

Cervical pain syndrome (CPS) is a set of symptoms limiting mobility in the upper back for more than a day. It is a common cause of disability. It is associated with poor posture, work in a sitting position, stress, and long-lasting and repetitive movements [1].

It is one of the most common painful conditions of the musculoskeletal system and the leading cause of illness and disability in everyday life and work activities worldwide. About $30-50 \%$ of adults experience neck pain at least once in their lives, and $10-15 \%$ of the population suffer from chronic ailments related to the current sedentary lifestyle [2,3].

Pain and disability caused by CPS and the tendency to recur significantly impact the individuals, their family, community, health-care system, and workplace. Accordingly, it

*Corresponding author: Eldad Kaljić, Department of physiotherapy, Faculty of Health Studies, University of Sarajevo, Stjepana Tomića 1, 71000

Sarajevo, Bosnia and Herzegovina. E-mail: eldad.kalji@@fs.unsa.ba

Submitted: 01 December 2020/Accepted: 25 May 2021

DOI: https://doi.org/10.17532/jhsci.2021.1142 represents a significant public health problem in terms of health and absence from work $[2,4]$.

The causes of neck pain can vary from inflammatory and degenerative rheumatic diseases, various traumatic conditions, and malignant diseases to mechanical causes arising from changes in the structural elements of the cervical spine [1].

The diagnosis of CPS is made based on the complete anamnesis and physical examination. Identified signs and symptoms may result in a definitive diagnosis or direct the patient to additional radiological, laboratory, or electrodiagnostic procedures $[1,5,6]$.

Somatic pain can be superficial or deep. Nociceptors activate superficial pain, and it is usually sharp and highly localized. Deep pain is diffuse, non-specific, and intensifies with neck movement, suggesting damage to deeper structures. In a larger number of patients, the pain is localized on the shoulder and upper arm, while fewer patients may experience headaches, especially in the frontal part. Neuropathic pain is caused by irritation of the nerve roots or spinal cord. It is sharp and burning in nature and is manifested by a combination of neck pain (73\%), pain that spreads through 
the arms (99\%), or pain in the scapular region (52\%). Dysesthesia, paresthesia, and allodynia are associated with it $[7,8]$. It can be acute, subacute, and chronic CPS with symptoms that last more than 12 weeks concerning the duration of pain $[9,10]$.

Most acute episodes disappear spontaneously without treatment, but almost $50 \%$ of patients experience a recurrent episode of neck pain at some point in their lives [2]. Therefore, the main goal of the treatment is to reduce the intensity of pain and fully train the patient in performing daily life and work activities [5]. For this purpose, conservative treatment is recommended, which may initially, depending on the cause, vary from an individually determined period of rest and medical therapy $[11,12]$ to the procedures of joint mobilization, techniques for reducing pain intensity, relaxation, and soft-tissue recovery (physical therapy, dry needling, instrument assisted soft-tissue mobilization - IASTM, and neurodynamics) $[7,8,13,14]$.

An indispensable part of neck pain treatment is the alternative treatment (acupuncture) and psychosocial techniques $[5,15,16]$.

Kinesitherapy in the form of exercises for maintaining the range of motion and strengthening the cervical spine muscles leads to the correction of posture, reduction of discomfort, and prevention of neck pain recurrence [17].

In rare cases, when conservative treatment does not achieve satisfactory results or when there is an absolute indication, surgical treatment is recommended [5].

The occurrence of pain by CPS has a negative impact on daily life activities in limiting functional mobility and reducing the quality of life [18]. It is also a common problem in the working population and mainly affects office workers. The continuous sitting position can lead to significant pressure on the back muscles, discs, and ligaments, causing structural changes in the spinal column, leading to the appearance of pain in the cervical spine [19].

The aim of this study was to examine the effect of physical therapy on the pain intensity, the degree of disability, and the daily life and work abilities of people with chronic CPS.

\section{METHODS}

The research included 50 respondents of both genders, more than 18 years old, and all occupations, who came to the health spa center "Reumal" Fojnica because of the chronic CPS symptoms from June 16, 2020, until July 10, 2020.

Criteria for inclusion of respondents in the study were as follows:

- Chronic CPS is diagnosed by clinical examination and radiological examinations (X-ray, CT, and MRI)

- Research instruments performed the analysis of the disability degree, pain intensity, and daily life and work activities before inclusion in the research.

The criteria for exclusion from the study were as follows:

- $\quad$ Respondents under 18 years of age

- The research instruments did not analyze disability, pain intensity, and daily life and work activities after the physical therapy program
- Discontinuation of treatment or non-adherence to therapeutic protocol.

During the first examination and the control examination after the treatment of the respondents, the following analysis was made:

- Degree of disability of the respondents due to neck pain using the "Northwick Park Neck Pain" questionnaire [20]

- The respondents who were sedentary or standing workers were working abilities using the Cornell University questionnaire on musculoskeletal discomfort [21]

- The intensity of pain and daily life activities using the "Northwick Park Neck Pain" questionnaire [20].

Treatment of all subjects included physical therapy procedures applied in the following order:

- Transcutaneous electrical nerve stimulation (TENS), standard high frequency $(75-100 \mathrm{~Hz}, 200 \mu \mathrm{s})$ for 20 minutes each day of therapy. A two-channel method was used using four skin electrodes applied paravertebrally on both sides (C5-TH1 area)

- Magnetotherapy, a low-frequency magnetic field applied to the cervical and upper thoracic segments using a $70 \mathrm{~cm}$ diameter solenoid for 20 minutes each day of therapy

- Therapeutic ultrasound, continuous ultrasound waves of intensity $0.4-0.8 \mathrm{~W} / \mathrm{cm}^{2}$ for 4 minutes, 10 procedures for the first 10 days of therapy (each day for subjects on therapy for $<10$ days) applied paravertebrally the shoulder girdle muscles on both sides

- Kinesitherapy in the form of McKenzie exercises lasting 20 minutes each day of therapy.

The research was designed as a pre- and post-treatment study that analyzed the condition of the subjects at the first examination and the control examination after the treatment was completed. Respondents performed a kinesitherapy program in the form of McKenzie exercises under the supervision of the same physiotherapist. At the same time, TENS, magnetotherapy, and therapeutic ultrasound were administered by physiotherapists in charge of conducting them during the study period.

\section{Ethics approval}

The study was approved by the Ethics Committee of the Faculty of Health Studies number 04-7-4/20. It was conducted exclusively voluntarily, and we received consent for participation from each respondent. The identities of the respondents are classified concerning ethical principles and the principles of privacy.

Statistical analysis of the data was performed in IBM SPSS Statistics v. 24.0. for Windows. The results are presented in the form of tables and Graph 1.

When describing the samples, we used the appropriate methods of classical descriptive statistics:

- $\quad$ Average value $(\mathrm{M})$

- $\quad$ Standard deviation (SD)

- Absolute frequencies (N)

- $\quad$ Relevant frequencies (\%)

Before the primary analyses, we checked how the results were distributed and based on the Kolmogorov-Smirnov 


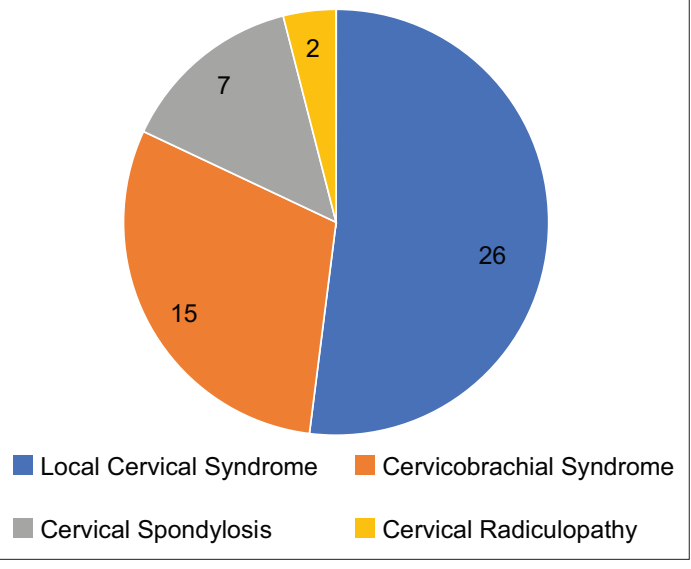

GRAPH 1. Display of the most common diagnoses.

and Shapiro-Wilk tests results. We found out that all measured variables deviated from the normal distribution to a statistically significant extent, $p<0.05$. That is why we used non-parametric statistics to calculate the existence of statistically significant differences.

\section{RESULTS}

Of the total number of respondents included in the study, $13(26 \%)$ respondents were male and $37(74 \%)$ were female (Table 1).

The respondents' age structure determined the average age of the respondents, which was $\mathrm{M}=57.36(\mathrm{SD}=12.11)$, where the youngest respondent was 28 and the oldest 77 years old (Table 2 ).

Of the total number of the respondents, 33 (66\%) were unemployed, while 17 (34\%) were employed (Table 3).

Of the total number of the respondents, 26 (52\%) had a diagnosis of the local cervical syndrome, 15 (30\%) had a diagnosis of cervicobrachial syndrome, 7 (14\%) had a diagnosis of cervical spondylosis, and $2(4 \%)$ had a diagnosis of cervical radiculopathy (Graph 1).

The average duration of the physical therapy program was $\mathrm{M}=10.94$ days (Table 4)

\section{Results analysis of the disability degree caused by} neck pain (Northwick Park Neck Pain questionnaire)

The average value of the degree of disability of the respondents before rehabilitation was $40 \%$, and after the rehabilitation, $30 \%$, so there was a decrease in the disability degree (Table 5).

The results of the Wilcoxon test show that $p<0.05$, which means that there is a statistically significant difference, and the degree of pain after the rehabilitation is statistically significantly lower than the degree of pain before the rehabilitation (Table 6).

\section{Results analysis of the workability of the respondents (Cornell University questionnaire on musculoskeletal discomfort)}

To analyze the Cornell University questionnaire on musculoskeletal discomfort, which was used to assess workability, we used employed respondents whose number is presented in Table 7.
TABLE 1. Gender structure of the respondents

\begin{tabular}{lcc}
\hline Gender & $n$ & $\%$ \\
\hline Male & 13 & 26 \\
Female & 37 & 74 \\
Total & 50 & 100 \\
\hline
\end{tabular}

TABLE 2. The average age of the respondents

\begin{tabular}{ccccc}
\hline & M & SD & Min & Max \\
\hline Age & 57.36 & 12.11 & 28.00 & 77.00 \\
\hline
\end{tabular}

TABLE 3. Working status of the respondents

\begin{tabular}{lcc}
\hline Working status & $n$ & $\%$ \\
\hline Unemployed & 33 & 66 \\
Employed & 17 & $34 \%$ \\
\hline
\end{tabular}

TABLE 4. Display of the duration of the physical therapy program

\begin{tabular}{|c|c|c|}
\hline Duration of the physical therapy program & $n$ & $\%$ \\
\hline 10 days & 37 & 74 \\
\hline 12 days & 1 & 2 \\
\hline 13 days & 3 & 6 \\
\hline 14 days & 3 & $6 \%$ \\
\hline 15 days & 1 & 2 \\
\hline 16 days & 1 & 2 \\
\hline 20 days & 1 & 2 \\
\hline 21 days & 1 & 2 \\
\hline 5 days & 1 & 2 \\
\hline 7 days & 1 & 2 \\
\hline
\end{tabular}

TABLE 5. Degree of disability before and after the rehabilitation

\begin{tabular}{lcccc}
\hline Degree of disability & M & SD & Min & Max \\
\hline $\begin{array}{l}\text { Degree of disability before } \\
\text { the rehabilitation }\end{array}$ & 40 & 20 & 9.3 & 77.070 \\
$\begin{array}{l}\text { Degree of disability after the } \\
\text { rehabilitation }\end{array}$ & 30 & 10 & 5.5 & 57.070 \\
\hline
\end{tabular}

TABLE 6. Statistical significance of the disability degree before and after rehabilitation

\begin{tabular}{lc}
\hline $\begin{array}{l}\text { Statistical } \\
\text { significance }\end{array}$ & $\begin{array}{l}\text { Degree after the rehab - } \\
\text { Degree before the rehab }\end{array}$ \\
\hline$Z$ & -5.908 \\
$P$ & 0.000 \\
\hline
\end{tabular}

By analyzing the total number of 17 (34\%) employed respondents, we reached the results by which 5 respondents (12\%) were sedentary workers, and 12 respondents (71\%) were standing workers.

Before the rehabilitation, the most significant number of employed respondents, 59\%, answered that the occurrence of discomfort and unpleasantness due to the symptoms of chronic CPS slightly interfered with their work.

After the rehabilitation, the most significant number of employed respondents, 53\%, answered that the appearance of discomfort and unpleasantness due to the symptoms of chronic CPS did not interfere with their work at all. Therefore, concerning the slight interference before the rehabilitation, we could see that there had been an improvement after rehabilitation (Table 8).

The table shows the descriptive values of the measures of work interference before and after the rehabilitation. Based on the 
arithmetic mean values, we see that the discomfort caused by chronic CPS was less disruptive to work after rehabilitation than the level measured before the rehabilitation (Table 9).

The results of the Wilcoxon test show that $p<0.05$, which means that there is a statistically significant difference between conditions before and after the rehabilitation, that is, after the rehabilitation, there was a statistically significant reduction of work interference (Table 10).

\section{Analysis of the pain intensity and daily life activities (Northwick Park Neck Pain questionnaire)}

In the research, we analyzed the intensity of pain and daily life activities: Pain and sleep, carrying objects, reading and watching TV, work, and social activities.

We presented the descriptive values of the measured variables for pain intensity, pain, and sleeping, carrying objects, reading and watching TV, work, and social activities before and after the rehabilitation. Based on the presented arithmetic means, we see a decrease in measured values after the rehabilitation concerning values measured before the rehabilitation (Table 11).

Based on the ranks of the arithmetic means, we checked whether the stated differences in the measured values before and after rehabilitation were statistically significant.

The Wilcoxon test results show a statistically significant difference $p<0.05$ for all measured variables when comparing the values before and after the rehabilitation. This means that rehabilitation led to a statistically significant decrease in values than values measured before the therapy (Table 12).

TABLE 7. Standing/sitting position

\begin{tabular}{lcc}
\hline Position during work & $n$ & $\%$ \\
\hline Sitting position during work & 5 & 29 \\
Standing position during work & 12 & 71 \\
\hline
\end{tabular}

TABLE 8. Interference with work before the rehabilitation

\begin{tabular}{lcc}
\hline Interference with work & $n$ & $\%$ \\
\hline Interference with work before the rehabilitation & & \\
None & 2 & 12 \\
Insignificant interference & 10 & 59 \\
Significant interference & 5 & 29 \\
Interference with work after the rehabilitation & & \\
None & 9 & 53 \\
Insignificant interference & 8 & 47 \\
Significant interference & 0 & 0 \\
\hline
\end{tabular}

TABLE 9. Descriptive values of interference variables before and after the therapy

\begin{tabular}{lcccc}
\hline Interference with work & $\mathrm{M}$ & $\mathrm{SD}$ & $\mathrm{Min}$ & $\mathrm{Max}$ \\
\hline Interference with work before & 1.2 & 0.6 & 0 & 2 \\
Interference with work after & 0.5 & 0.5 & 0 & 1 \\
\hline
\end{tabular}

TABLE 10. Statistical significance of work interference before and after the therapy

\begin{tabular}{lc}
\hline Statistical significance & $\begin{array}{c}\text { Interference with work after - } \\
\text { Interference with work before }\end{array}$ \\
\hline$Z$ & -3.464 \\
$P$ & 0.001 \\
\hline
\end{tabular}

\section{DISCUSSION}

The analysis of gender structure determined that 13 male respondents, $26 \%$, and 37 female respondents, $74 \%$, participated in the research. In addition, the analysis of the age structure of the respondents determined the average age of the respondents, which was $\mathrm{M}=57.36$ ( $\mathrm{SD}=$ 12.11), where the youngest respondent was 28 and the oldest 77 years old.

Out of the total number of respondents, $33(66 \%)$ are unemployed and 17 (34\%) are employed. The analysis of the structure of respondents by occupation shows that out of $34 \%$ of employed respondents, $5(12 \%)$ were sedentary and $12(71 \%)$ had standing workers.

All subjects included in the research had chronic pain, and the average duration of the rehabilitation was $\mathrm{M}=10.94$ days.

Analysis of the Northwick Park Neck Pain questionnaire presented the disability degree before starting rehabilitation treatment and after the end of rehabilitation treatment.

The average value of the disability degree calculated using the Northwick Park Neck Pain questionnaire before rehabilitation was $40 \%$ and after rehabilitation $30 \%$. Wilcoxon test shows that $Z=-5.908(p<0.05)$, which means a statistically significant difference. Therefore, the degree of disability after rehabilitation is statistically significantly lower than the degree of disability before rehabilitation.

Bernal-Utrera (2020) et al. investigated the effects of manual therapy and therapeutic exercises in treating chronic CPS. A randomized control study involving 69 subjects divided into three age groups of $18-50$ years examined the effects of these procedures in the $1^{\text {st }}, 4^{\text {th }}$, and $12^{\text {th }}$ weeks. Research has shown that both methods reduce the pain intensity and the disability degree after 12 weeks, with therapeutic exercises having a faster effect on reduced disability degree than manual therapy [22].

Sial et al. (2016) researched the effectiveness of physical therapy and home exercise programs to reduce neck discomfort in the treatment of postural neck pain. The research included 40 patients of both genders, divided into the experimental (physical therapy and home exercise program for the cervical spine) and the control group (physical therapy). The research instrument was the NDI questionnaire. By analyzing the gender structure of the respondents, it was determined that most of the respondents were female,

TABLE 11. Descriptive values of measured variables of pain intensity and daily life activities

\begin{tabular}{lcccc}
\hline Pain intensity and daily activities & M & SD & Min & Max \\
\hline Pain intensity before & 2.2 & 0.8 & 1 & 4 \\
Pain intensity after & 1.2 & 0.6 & 0 & 3 \\
Pain and sleeping before & 1.5 & 0.9 & 0 & 3 \\
Pain and sleeping after & 0.8 & 0.5 & 0 & 2 \\
Carrying objects before & 2.5 & 0.9 & 0 & 4 \\
Carrying objects after & 1.7 & 0.9 & 0 & 3 \\
Reading and watching TV before & 1.2 & 0.8 & 0 & 3 \\
Reading and watching TV after & 0.7 & 0.5 & 0 & 2 \\
Work before & 1.5 & 0.8 & 0 & 4 \\
Work after & 0.9 & 0.5 & 0 & 2 \\
Social activities before & 1.1 & 0.8 & 0 & 2 \\
Social activities after & 0.7 & 0.5 & 0 & 2 \\
\hline
\end{tabular}


TABLE 12. Statistical significance of the measured variables

\begin{tabular}{lcccccc}
\hline $\begin{array}{l}\text { Statistical } \\
\text { significance }\end{array}$ & $\begin{array}{c}\text { Pain intensity after } \\
\text { - Pain intensity } \\
\text { before }\end{array}$ & $\begin{array}{c}\text { Pain and sleeping } \\
\text { after - Pain and } \\
\text { sleeping before }\end{array}$ & $\begin{array}{c}\text { Carrying after - } \\
\text { Carrying before }\end{array}$ & $\begin{array}{c}\text { Reading and watching } \\
\text { TV after- Reading and } \\
\text { watching TV before }\end{array}$ & $\begin{array}{c}\text { Work after - } \\
\text { Work before }\end{array}$ & $\begin{array}{c}\text { Social activities after } \\
- \text { Social activities } \\
\text { before }\end{array}$ \\
\hline Z & -6.051 & -4.919 & -4.319 & -4.347 & -5.070 \\
$P$ & 0.000 & 0.000 & 0.000 & 0.000 & 0.000 \\
\hline
\end{tabular}

61.1\%. Furthermore, according to the sample frequency, most were office, field, and house workers. The research concluded that the home program of exercises for reducing discomfort in the cervical spine had significant effects on reducing postural neck pain [23].

Out of the 50 respondents included in our research, 17 were employed. Out of those 17, 5 respondents were sedentary workers and 12 respondents were standing workers. We analyzed the extent to which discomfort and discomfort interfered with work activities before and after the rehabilitation program among the employed respondents. Most employed respondents (59\%) answered that the neck pain slightly interfered with their work. However, when the respondents completed the rehabilitation procedures, the most significant number $(53 \%)$ responded that the neck pain did not interfere with their work. Wilcoxon test $Z=-3.464(p<0.055)$ showed a statistically significant difference in the domain of disruption of work caused by neck pain before and after rehabilitation. Physiotherapy procedures also affected the field of improving the working status of subjects with chronic neck pain.

We analyzed the pain intensity and parameters of daily life activities using the Northwick Park Neck Pain questionnaire: Pain and sleeping, carrying objects, reading and watching TV, work, and social activities before and after the rehabilitation program.

The average value of neck pain intensity before the therapy was $M=2.2$, and after the therapy, $M=1.2$. Wilcoxon test showed that $Z=-6.051(p<0.05)$, which means that there is a statistically significant difference when comparing the pain intensity before and after the rehabilitation.

The average value of the neck pain intensity that affected sleeping of the respondents before the therapy was $M=1.5$, and after the therapy, it was $M=0.8$. The results of the Wilcoxon test showed that $Z=-4.919(p<0.05)$, and therefore, there was a statistically significant difference in sleeping disorders caused by pain before and after the rehabilitation.

Neeraj and Shiv (2016) discussed the importance of McKenzie exercises to treat symptoms caused by neck pain in their research. They compared the impact of McKenzie exercises, strengthening exercises, and the application of warm hydrocollator packs. Research tools were VAS and Functional Rating Index (FRI). The study included 45 respondents who were divided into three groups. The first group of the respondents had McKenzie exercises treatment and application of warm packs. The second group of the respondents made strengthening exercises, application of warm packs, and postural correction, while the third group used warm packs and postural correction. The period of the rehabilitation was 4 weeks. Respondents were examined with the help of instruments before the start of the rehabilitation and after the rehabilitation. Statistical analysis did not show a significant difference in relation to age and body weight. However, a significant statistical difference was established by VAS and FRI analysis $(p<0.05)$ in the rehabilitation period from the $2^{\text {nd }}$ to the $4^{\text {th }}$ week in all three groups of subjects. A significant statistical difference $(p<0.05)$ was also established between the first and third group in the rehabilitation period from the $2^{\text {nd }}$ to the $4^{\text {th }}$ week. The treatment with McKenzie exercises was more effective than strengthening exercises and applying warm packs in the period from the $2^{\text {nd }}$ to the $4^{\text {th }}$ week of the rehabilitation [24].

Respondents had a lower ability to carry objects before the treatment $(\mathrm{M}=2.5)$ than the period after the treatment $(\mathrm{M}=1.7)$. Wilcoxon test showed that $\mathrm{Z}=-4.319$ $(p<0.05)$, which means that there is a statistically significant difference in carrying objects in periods before and after the rehabilitation.

Pain and discomfort in the neck while reading and watching TV were more emphasized in respondents before the treatment $(\mathrm{M}=1.2)$ than the period after the treatment $(M=0.7)$. Wilcoxon test showed that $Z=-4.347(p<0.05)$, which means a statistically significant difference in performing these activities before and after the rehabilitation.

Neck pain significantly interfered with the respondents' work activities before the treatment $(M=1.5)$, and after the treatment, there was a significant improvement $(M=0.9)$. According to the Wilcoxon test $Z=-5.070(p<0.05)$, there is a statistically significant difference in performing work before and after the rehabilitation.

Neck pain significantly limited the social activities of the respondents before the therapy $(\mathrm{M}=1.1)$ when we compare it to the period after the therapy $(\mathrm{M}=0.7)$ according to Wilcoxon test $Z=-3.629(p<0.05)$, and there is a statistically significant difference in social life activities before and after the rehabilitation.

Our statistical analysis determined a significant statistical difference in the reduced pain intensity and the performance of daily life activities before therapy beginning and after the completion of the rehabilitation program. We compared these results with some of the studies.

O'Riordan et al. (2014) conducted a systematic review of the literature and a meta-analysis on the efficiency of an active physiotherapy exercise program in patients with chronic neck pain. Within the study, 16 studies were selected that met the inclusion criteria, and treatment outcomes were analyzed, including isometric strength, Neck Disability Index score, and pain intensity score. The research concluded that physiotherapeutic interventions that use a multimodal approach are beneficial in increasing strength, improving function and quality of life, and reducing pain intensity in people with chronic neck pain. Furthermore, it was determined that active strengthening exercises were useful in achieving these effects and that they 
could be enhanced by the inclusion of stretching and aerobic exercises [25].

\section{CONCLUSION}

Based on the conducted research, it was determined that physical therapy procedures effectively reduce the degree of disability of people with chronic CPS. By analyzing the functional ability, we realized that the discomfort caused by the symptoms of chronic CPS, which impaired the working ability of the respondents, significantly decreased after the physical therapy program. The implemented therapeutic program effectively reduced pain intensity and improved daily life, work, and social activities in people with chronic CPS.

\section{ACKNOWLEDGMENT}

We want to express our gratitude to Northwick Park Hospital in Middlesex, England, for using the Northwick Park Neck Pain Questionnaire. We also express gratitude to Human Factors and Ergonomics Laboratory at Cornell University for permission to use the Cornell Musculoskeletal Discomfort Questionnaire for sedentary and standing worker (female and male version).

\section{DECLARATION OF INTERESTS}

Authors declare no conflict of interest.

\section{REFERENCES}

1. Côté P, Alleyne J, McIntosh GA. Pain in the neck. J Curr Clin Care 2015;5(1):25-33.

2. Tsakitzidis G, Remmen R, Dankaerts W, Royen P. Non-specific neck pain and evidence-based practice. Eur Sci J 2013;9(3):1-3.

3. Genebra C, Maiel N, Bento T, Simeao S, Vitta A. Prevalence and factors associated with neck pain: A population-based study. Braz J Phys Ther 2017;21(4):274-80. https://doi.org/10.1016/j.bjpt.2017.05.005

4. Hoy D, March L, Woolf A, Blyth F, Brooks P, Smith E, et al. The global burden of neck pain: Estimates from the global burden of disease 2010 study. Ann Rheum Dis 2014;73(7):1309-15.

https://doi.org/10.1136/annrheumdis-2013-204431.

5. Steven $\mathrm{P}$, Cohen M. Epidemiology, diagnosis, and treatment of neck pain. Mayo Clin Proc 2015;90(2):284-99.

6. Malanga A, Tran J, Maharjan S. Neck pain: Diagnosis and management. Pract Pain Menag 2012;12(9). https://www.practicalpainmanagement.com/pain/spine/ neck-pain-diagnosis-management (20.07.2020.)

7. Kim J, Sung D, Lee J. Therapeutic effectiveness of instrument-assisted soft tissue mobilization for soft tissue injury: Mechanisms and practical application. J Exerc Rehabil 2017;13(1):12-22.

https://doi.org/10.12965/jer.1732824.412.
8. Ernst M, Schallert W. Reliabilität und validität des upper limb neurodynamic tests bei symptomatischen nackenpatienten. Manuelle Ther 2013;17:27-38.

https://doi.org/10.1055/s-0033-1334134.

9. Vijiaratnam N, Bertram K. Neck pain: What if it is not musculoskeletal? Aust J Gen Pract 2018;47(5):279-81.

https://doi.org/10.31128/afp-10-17-4358.

10. Khelemsky Y, Malhotra A, Gritsenko K. Academic Pain Medicine. Switzerland: Springer; 2019. p. 219.

11. Machado G, Maher C, Ferreira P, Day R, Pinheiro M, Ferreira M. Non-steroidal anti-inflammatory drugs for spinal pain: A systematic review and meta-analysis. Clin Epidemiol Res 2017;76(7):1269-78.

https://doi.org/10.1136/annrheumdis-2016-210597.

12. Buchbinder $R$, Mitchell $C$. Pain in the neck, shoulder and arm. In: $A B C$ of Rheumatology. Hoboken: Blackwell Publishing Ltd.; 2010. p. 12.

13. Babić-Naglić $\bigoplus$. Fizikalna I Rehabilitacijska Medicina. Croatia: Medicinska Naklada Zagreb; 2013.

14. Gattie E, Cleland J, Snodgrass S. Dry needling for patients with neck pain: Protocol of a randomized clinical trial. JMIR Res Protoc 2017;6(11):e227. https://doi.org/10.2196/resprot.7980

15. Zhang Q, Yue Y, Zeng X, Sun Z, Golianu B. Acupuncture for chronic neck pain: A protocol for an updated systematic review. Syst Rev 2016;5:76. https://doi.org/10.1186/s13643-016-0257-x.

16. Eccleston C, Morley SJ, Williams AC. Psychological approaches to chronic pain management: Evidence and challenges. Br J Anaesth 2013;111(1):59-63. https://doi.org/10.1093/bja/aet207.

17. Šljivo I. Učinak Izolirane Kineziterapije Na Funkcijski Nalaz Bolesnika Sa Vertebrogenim Bolnim Sindromom Vratne Kralježnice. Završni Rad. Sveučilište u Splitu; 2014.

18. Altug F, Büker N, Kavlak E, Kit Siş A, Cavlak U. Relationship between disability, pain intensity and quality of life in patients with chronic neck pain. Rev Română Kinetoterapie 2013;19(31):69-72.

19. Chen X, Coombes B, Sjøgaard G, Jun D, O'Leary S, Johnston V. Workplace-based interventions for neck pain in office workers: Systematic review and meta-analysis. Phys Ther 2018;99(1):40-62.

https://doi.org/10.1093/ptj/pzx101.

20. Leak AM, Cooper J, Dyer S, Williams KA, Stokes L, Frank AO. The Northwick park neck pain questionnaire, devised to mesure neck pain and disability. Br J Rheumatol 1994;33(5):469-74.

https://doi.org/10.1093/rheumatology/33.5.469.

21. Hedge A, Morimoto S, McCrobie D. Cornell Musculoskeletal Discomfort Questionnaires (CMDQ), Cornell University Ergonomics Web; 1994 https://doi.org/10.1037/t60061-000.

22. Bernal-Utrera C, Gonzalez-Gerez JJ, Anarte-Lazo E, Rodriguez-Blanco C. Manual therapy versus therapeutic exercise in non-specific chronic neck pain: A randomized controlled trial. Trials 2020;21(1):682. https://doi.org/10.1186/s13063-020-04610-w.

23. Sial AB, Kumar V, Reeta R, Kumar U, Puri J, Kumar K. Effectiveness of physical therapy in postural neck pain with and without home based management. J Sports Phys Educ 2016;3(4):66-87. https://doi.org/10.9790/6737-03046687.

24. Neeraj K. Shiv V. To compare the effect of strengthening neck exercise and mckenzie neck exercise in neck pain subject. Br J Med Health Res 2016;3(10):70-6.

25. O'Riordan C, Clifford A, van de Ven P, Nelson J. Chronic neck pain and exercise interventions: Frequency, intensity, time, and type principle. Arch Phys Med Rehabil 2014;95(4):770-83.

https://doi.org/10.1016/j.apmr.2013.11.015

\section{RELATED ARTICLES PUBLISHED IN JHSCI}

1. Katana B, Jaganjac A, Bojičić S, Mačak Hadžiomerović A, Pecar M, Kaljić E, Muftić M. Effectiveness of physical treatment at De Quervain's disease. JHSCI. 2012;2(1):80-4.

2. Kaljić E, Avdić D, Pecar M, Trtak N, Katana B, Kaljić N. Efficiency of trunk stabilizing exercises in treatment of patients with lumbar pain syndrome. JHSCI.2014;3(3):216-21.

3. Trebinjac S, Kitchbi H. Long-term effect of Prolotherapy on symptomatic rotator cuff tendinopathy. JHSCI. 2015;5(3):93-8.

4. Jaganjac A, Katana B, Bojicic S, Macak Hadziomerovic A, Avdic D, Svraka E, Majstorović M. Rehabilitation of patients with rheumatoid arthritis treated in stationary spa treatment. JHSCI].2015;5(1):25-30.

5. Kapetanovic A, Jerkovic S, Avdic D. Effect of core stabilization exercises on functional disability in patients with chronic low back pain. JHSCI. 2016;6(1):59-66. 